Check for updates

Cite this: RSC Adv., 2018, 8, 25568

\title{
Flexible polypyrrolone-based microporous carbon nanofibers for high-performance supercapacitors
}

\author{
Shuwu Liu, Yue Zeng, Hong Fang, Qiaohui Guo, (D)* Ling Sui and Haoqing Hou* \\ Flexible materials have drawn considerable attention due to the demand for wearable and flexible electronic \\ products. Seeking new kinds of precursors for preparing carbon nanofibers with good flexibility for high- \\ performance supercapacitors is a hot issue. In this work, a flexible polypyrrolone (BBB)/polyimide (PI) \\ composite-based carbon nanofiber membrane (PBPICF) is prepared by a facile electrospinning and \\ carbonization process. The PBPICF membranes exhibit a three-dimensional (3D) porous, fluffy and self- \\ standing structure with good mechanical performance and flexibility, and can be arbitrarily bent and \\ folded. PBPICF-65-35 (consisting of BBB (65 wt\%) and PI (35 wt\%)) exhibits a high specific capacitance of \\ $172.44 \mathrm{~F} \mathrm{~g}^{-1}$ in $6 \mathrm{M} \mathrm{KOH}$ aqueous solution, which is two-fold more than that of commercial \\ polyacrylonitrile-based carbon nanofibers. In addition, PBPICF-65-35 also displays good power density \\ $\left(90 \mathrm{~W} \mathrm{~kg}^{-1}\right.$ ) and energy density $\left(19.4 \mathrm{~W} \mathrm{~h} \mathrm{~kg}^{-1}\right)$, and the capacitance remains at 96\% even after 10000 \\ cycles at $1.0 \mathrm{~A} \mathrm{~g}^{-1}$. Therefore, the simple preparation and good capacitance performance of PBPICFs \\ make them a promising binder-free electrode for wearable supercapacitors.
}

Received 25th May 2018

Accepted 7th July 2018

DOI: $10.1039 / c 8 r a 04479 a$

rsc.li/rsc-advances

Nowadays, most flexible EDLC electrodes are mainly carbon

\section{Introduction}

Supercapacitors, which can provide a higher energy density than traditional capacitors and a higher power density than secondary batteries, are a new type of energy storage device. ${ }^{\mathbf{1 , 2}}$ Double-layer capacitors (EDLCs) are currently the featured supercapacitors on the market. A variety of carbonaceous materials, such as activated carbon, ${ }^{3-5}$ carbon aerogels, ${ }^{6-8}$ graphene, ${ }^{9-11}$ carbon nanotubes (CNTs) ${ }^{12-14}$ and carbon fibers $(\mathrm{CNFs})^{15-17}$ have been introduced as promising electrode materials for EDLCs. However, commercially available carbonaceous electrode materials for supercapacitors suffer from various limitations, such as the high cost of CNTs, the inferior capacitance performance of CNFs, and the fabrication complexity of graphene. Therefore, developing an active electrode material with high electrochemical capacitance as well as a lower fabrication cost and good mechanical strength with flexibility is necessary. ${ }^{18}$

In the last decade, high-performance flexible supercapacitor electrodes have received increasing research and industrial attention owing to their potential application in portable electrochemical devices, hybrid electrical vehicles, and medical devices. ${ }^{19}$ It is well known that the development of flexible supercapacitors is ultimately dependent on flexible electrode materials, which avoid using fluorine-based binders and toxic organic solvents, largely simplifying the fabrication process. $^{20}$

Department of Chemistry and Chemical Engineering, Jiangxi Normal University, Nanchang, Jiangxi 330022, China. E-mail: guoqiaohui@jxnu.edu.cn; Fax: +86-7918812-0536; Tel: +86-791-8812-0389 fabric-based or carbon cloth-based materials, but the diameter of these carbon materials is too large (about 5-15 $\mu \mathrm{m}$ ), which may result in a lot of invalid weight. ${ }^{21-23}$ On the other hand, electrospinning is one of the most straightforward and effective methods for generating carbon nanofibers with a diameter from tens of nanometers to several micrometers, which can be directly used as flexible and self-supporting electrode materials with a high surface area. ${ }^{24}$ For example, Le et $a .^{25}$ reported a porous hollow carbon nanofiber (PHCNF) using a styreneacrylonitrile (SAN) copolymer as the core and polyacrylic acid (PAA) as the shell by a co-axial electrospinning technique. The PHCNFs showed excellent electrochemical properties with a high specific capacitance of $221 \mathrm{~F} \mathrm{~g}^{-1}$ and superior cycling stability. Ferraris and co-workers prepared a novel binder-free electrode material derived from immiscible polymer blends of PBI/6FDA-DAM:DABA. ${ }^{26}$ The obtained CNFs showed a specific surface area as high as $3010 \mathrm{~m}^{2} \mathrm{~g}^{-1}$ with a specific capacitance of $142 \mathrm{~F} \mathrm{~g}^{-1}$. Recently, Zhang and co-workers ${ }^{27}$ reported a nitrogen-doped carbon membrane derived from polyimide (PI) as a free-standing electrode for flexible supercapacitors. The carbon $_{\mathrm{PI}}$ membrane with a high packing density $\left(0.89 \mathrm{~cm}^{-3}\right)$ and a high content of nitrogen exhibited an excellent volumetric capacitance of $159.3 \mathrm{~F} \mathrm{~cm}^{-3}$, a high rate capability and a long cycle life.

Polypyrrolone (BBB), whose molecular backbone possesses a rigid structure of multiple polycyclic molecules, exhibits many outstanding properties, such as high strength and corrosion resistance. Liu $^{28}$ found that BBB-based carbon nanofibers displayed excellent flexibility and many nitrogen groups, which 
meets the requirements for high-performance capacitors. However, due to their insolubility in organic solvents and the fact that they are difficult to process, ${ }^{29,30}$ there are few reports on BBB-based carbon nanofibers for supercapacitors. In this work, (BBB)/polyimide (PI) composite-based carbon nanofiber (PBPICF) membranes were prepared by an electrospinning and carbonization process. The results indicated that the PBPICF membranes displayed good flexibility with abundant micropores. Electrochemical tests suggested that PBPICF-65-35 displayed excellent EDLC performance.

\section{Experimental}

\subsection{Reagents}

1,4,5,8-Naphthalenetetracarboxylic acid (NTCA) was purchased from Zhenzhou Alfa Chem Co., Ltd. 3,3'-Diaminobenzidine (DAB), 3,3' ${ }^{\prime}$ 4, $4^{\prime}$-biphenyl tetracarboxylic dianhydride (BPDA) and 4,4'-diaminodiphenyl ether (ODA) were purchased from Changzhou Sunlight Pharmaceutical Co., Ltd. Polyacrylonitrile (PAN) was purchased from Sigma-Aldrich Chemical Co. (St. Louis, MO, USA).

\subsection{Preparation of PBPICFs}

The preparation process of PBPICF is shown in Scheme 1 . Firstly, polymer solutions of polycarboxylic acid ammonium salt (PCAAS) and polyamic acid (PAA) used for electrospinning were synthesized from NTCA and DAB, and BPDA and ODA, as reported in our previous study. ${ }^{13}$ Then, PCAAS (NTCA-DAB) and PAA (BPDA-ODA) were mixed with polyamic acid (PAA, BPDAODA) in certain proportions (95\%: $5 \%, 85 \%: 15 \%, 65 \%: 35 \%$, $50 \%: 50 \%, 35 \%: 65 \%, 15 \%: 85 \%$ and $5 \%: 95 \%)$. Then the mixed solution was electrospun by applying an electrical potential, with a collecting distance of $20 \mathrm{kV}$ and $30 \mathrm{~cm}$. The nanofibers were annealed at $150{ }^{\circ} \mathrm{C}\left(\mathrm{N}_{2}, 2{ }^{\circ} \mathrm{C} \min ^{-1}, 1 \mathrm{~h}\right)$ and $500{ }^{\circ} \mathrm{C}\left(\mathrm{N}_{2}, 2{ }^{\circ} \mathrm{C} \min ^{-1}, 2 \mathrm{~h}\right)$ and were carbonized at $800{ }^{\circ} \mathrm{C}\left(\mathrm{N}_{2}\right.$, $\left.5{ }^{\circ} \mathrm{C} \min ^{-1}, 0.5 \mathrm{~h}\right)$. The obtained carbon nanofiber membranes were denoted as PBPICF-95-5, PBPICF-85-15, PBPICF-65-35, PBPICF-50-50, PBPICF-35-65, PBPICF-15-85 and PBPICF-5-95. For comparison, PAN-based CNFs were prepared by the same process.

\subsection{Apparatus}

Surface morphology was characterized using a scanning electron microscope (SEM, Vega-3, Tescan). Surface area and pore

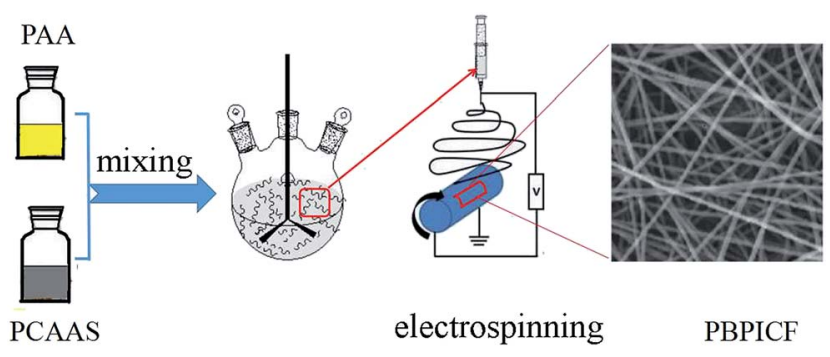

Scheme 1 Flow chart for the preparation of PBPICF. distribution were characterized by a physical adsorption instrument (ASAP 2020, Micromeritics Instrument Ltd., USA). Before the experiments, the samples were degassed under vacuum at $120^{\circ} \mathrm{C}$. The surface area was calculated using the BET equation. The pore-size distribution was calculated by the Density Functional Theory (DFT) method. Raman spectra of the carbonized materials were recorded on a Nicolet Almega XR Raman spectrometer equipped with a $780 \mathrm{~nm}$ laser. Thermogravimetric analysis (TGA, Beijing Henven Scientific Instrument Factory, China) was used to characterize the thermal stability $\left(50-800{ }^{\circ} \mathrm{C}, \mathrm{N}_{2}, 5{ }^{\circ} \mathrm{C} \mathrm{min}^{-1}\right)$. Microcomputer control universal testing (SANS, Shenzhen, China) was used to test the mechanical properties of the samples. The film samples for tensile testing were prepared and were $2 \mathrm{~mm}$ wide and $60 \mathrm{~mm}$ long. The samples were directly mounted to the sample clamps and

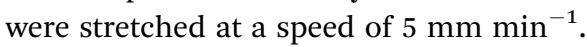

\subsection{Electrochemical performance}

The samples were packed with Ni foam with the same weight $(2.0 \mathrm{mg})$ in a sandwich-type test cell as the working electrode and the counter electrode. The reference electrode was $\mathrm{Hg} / \mathrm{HgO}$, and $6 \mathrm{M} \mathrm{KOH}$ solution was used as the electrolyte. The electrochemical properties were investigated using a CHI660 electrochemical workstation ( $\mathrm{CH}$ Instrument Inc). Cyclic Voltammograms (CV, voltage window: $-0.7-0.2 \mathrm{~V}$, scan rate: $50 \mathrm{mV} \mathrm{s}^{-1}$ ) and electrochemical impedance spectroscopy (EIS, frequency: $10^{-2}-10^{6} \mathrm{~Hz}$, amplitude: $5 \mathrm{~mA}$ ) were tested in a threeelectrode cell. Galvanostatic charge-discharge measurements (GCD) were based on a two-electrode system with a voltage window of $-0.7-0.2 \mathrm{~V}$.

\section{Results and discussion}

\subsection{Characterization}

As shown in Fig. 1A and B, the as-prepared nanofibers show a network structure with a uniform diameter (about 400-500 $\mathrm{nm})$. The PBPICF membrane also displays good flexibility and could be arbitrarily bent and folded without breaking. After folding from $0^{\circ}$ to $180^{\circ}$, the membrane still maintains its integrity (Fig. 1C-H). The reasons for this may be as follows: (1) the long and short molecules of the BBB chain were intertwined evenly, which induced better mechanical properties; (2) the membranes are fluffy and porous, which causes them to slide freely in the large micron-sized space once they are bent or folded, and the smooth surface benefits this free sliding.

Meanwhile, the flexibility of the membrane is affected by the ratio of PCAAS and PAA. The results (Fig. 2) suggest that if the content of PCAAS is low, the PBPICF membrane is more likely to become brittle, and a rupture is more obvious when the content of PCAAS is below 35\%. So the content of PCAAS in this study was between $50 \%$ and $95 \%$.

Fig. 3 shows the SEM images of the PCAAS/PAA nanofibers (Fig. 3A-D) and their carbon nanofibers (Fig. 3E-H). It can be seen that PBPICF shows a network structure with a uniform diameter and the diameter becomes smaller with the content of PAA increasing, from 500-650 nm for PBPICF-95-5 to 150- 

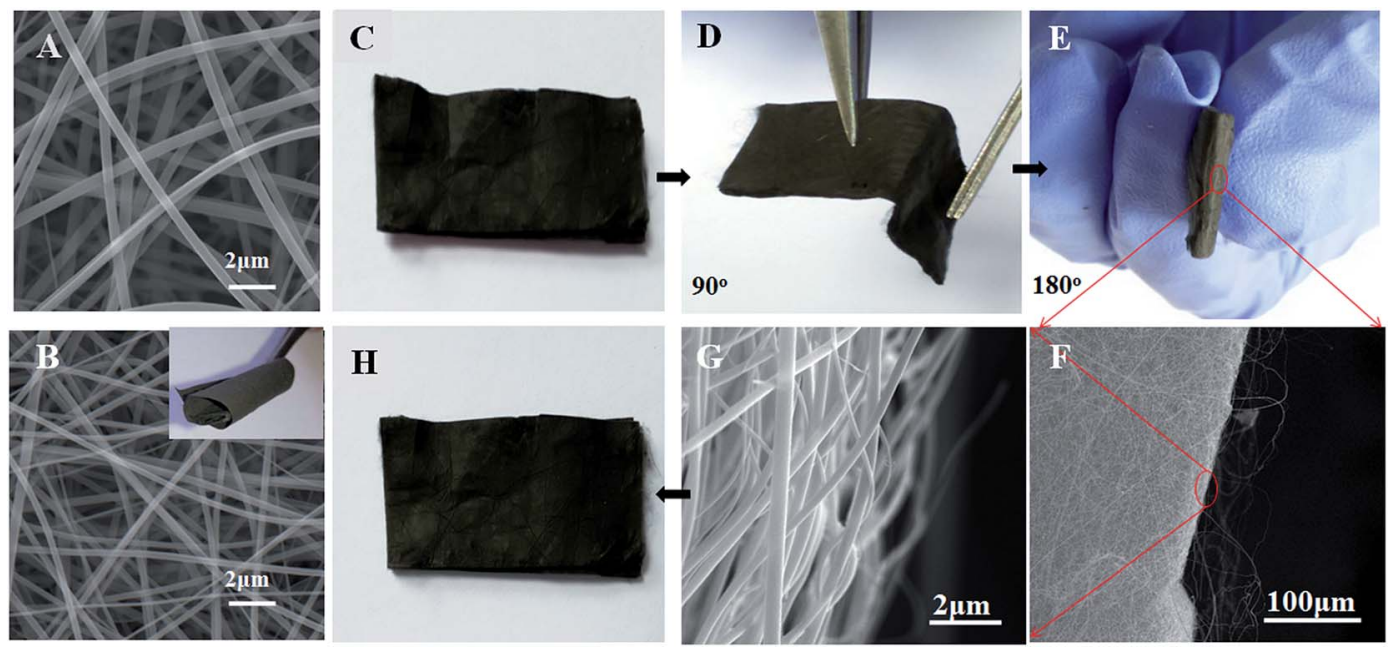

Fig. 1 SEM images of the PCAAS-PAA (65-35\%) composite nanofibers (A) and the PBPICF-65-35 membrane (B), photographs of (C) the PBPICF65-35 membrane, (D) the membrane folded $90^{\circ}$, (E) the membrane folded $180^{\circ}$ and $(H)$ the membrane restored; (F and $\left.G\right)$ are the SEM images of the PBPICF-65-35 membrane after folding $180^{\circ}$.

$200 \mathrm{~nm}$ for PBPICF-50-50, which may be due to the difference in the polymer molecular length between the two kinds of precursor. The PBPICF membranes could endure cyclic bending with good flexibility, which is favorable for the preparation of self-supporting electrodes (Fig. 3E-H). Fig. 3I-L show the longitudinal section views of PBPICF, which demonstrate that the membranes become tighter with a decrease in PCAAS, which is one of the reasons for the flexibility.

In order to understand whether the material is selfsupporting and if it has innate flexibility characteristics, its mechanical performance was investigated. Fig. 4A shows that the PBPICF membrane displays good strength (e.g. PBPICF-65$35,14.6 \mathrm{MPa})$ and elongation at break $(94 \%)$. The results suggest that it meets the self-supporting requirements. Among them, PBPICF-65-35 displays optimum mechanical properties.
Specific surface area $\left(S_{\mathrm{BET}}\right)$ and pore size distribution are two critical factors for the charge storage performance of EDLCs. Recently, the Yury group ${ }^{31}$ found that carbon materials with a pore size of $0.6 \mathrm{~nm}$ held $50 \%$ more charge than that of powder carbon materials, which indicated that the ions of the electrolyte could enter into pore canals of less than $2 \mathrm{~nm}$ with the help of desolvation. Therefore, both an appropriate pore size distribution and a high surface area are necessary for highperformance EDLCs. Fig. 4B shows that the isothermal adsorption curve of PBPICF belongs to the I type, which has micropore characteristics. The $S_{\mathrm{BET}}$ of PBPICF becomes larger as the BBB content decreases, and the $S_{\mathrm{BET}}$ values are $63.14 \mathrm{~m}^{2}$ $\mathrm{g}^{-1}, 168.02 \mathrm{~m}^{2} \mathrm{~g}^{-1}, 368.00 \mathrm{~m}^{2} \mathrm{~g}^{-1}$ and $534.30 \mathrm{~m}^{2} \mathrm{~g}^{-1}$ for PBPICF-95-5, PBPICF-85-15, PBPICF-65-35 and PBPICF-50-50, respectively. The pore size distribution of PBPICF-65-35 is centered at $0.6 \mathrm{~nm}$ with the largest pore volume (Fig. 4C), which

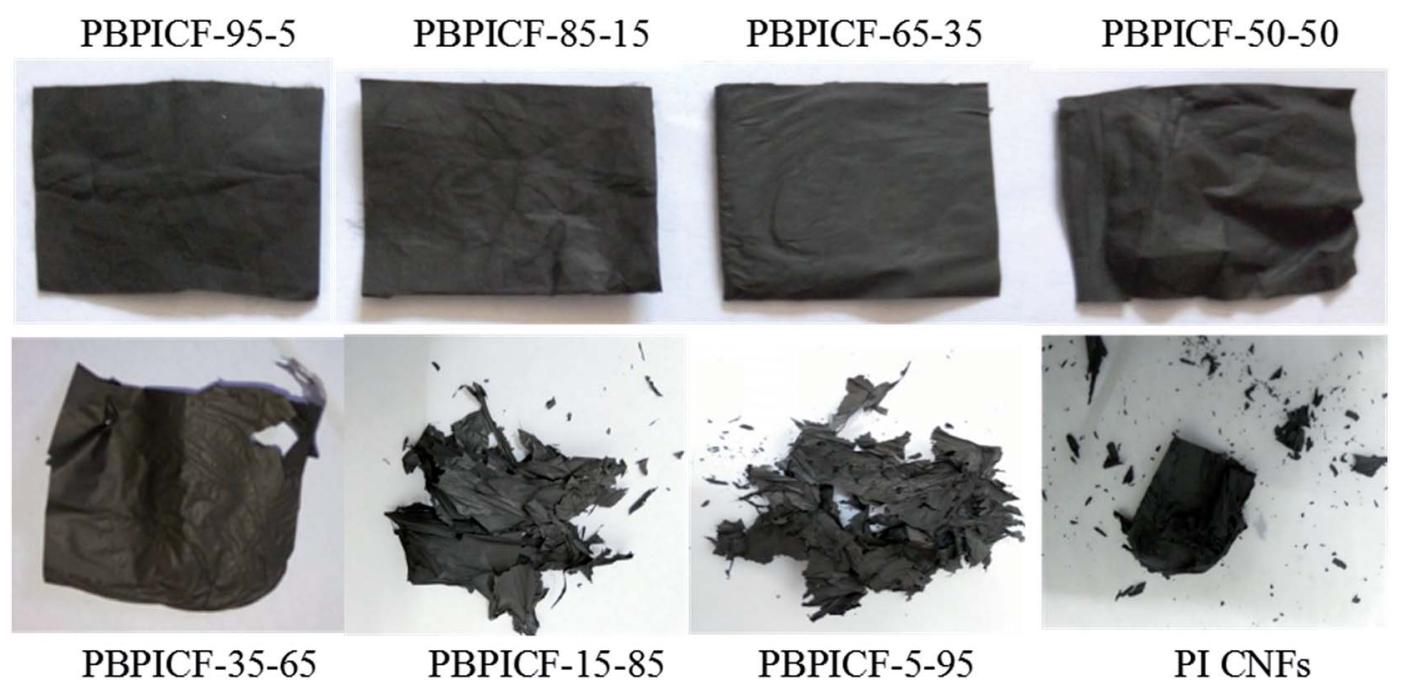

Fig. 2 Photographs of the PBPICF membranes. 


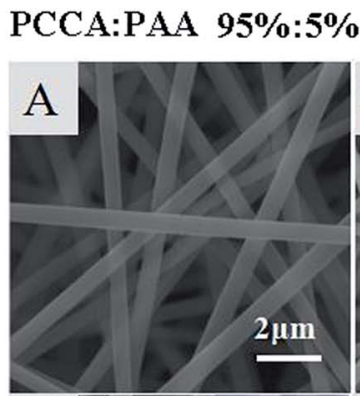

85\%:15\%
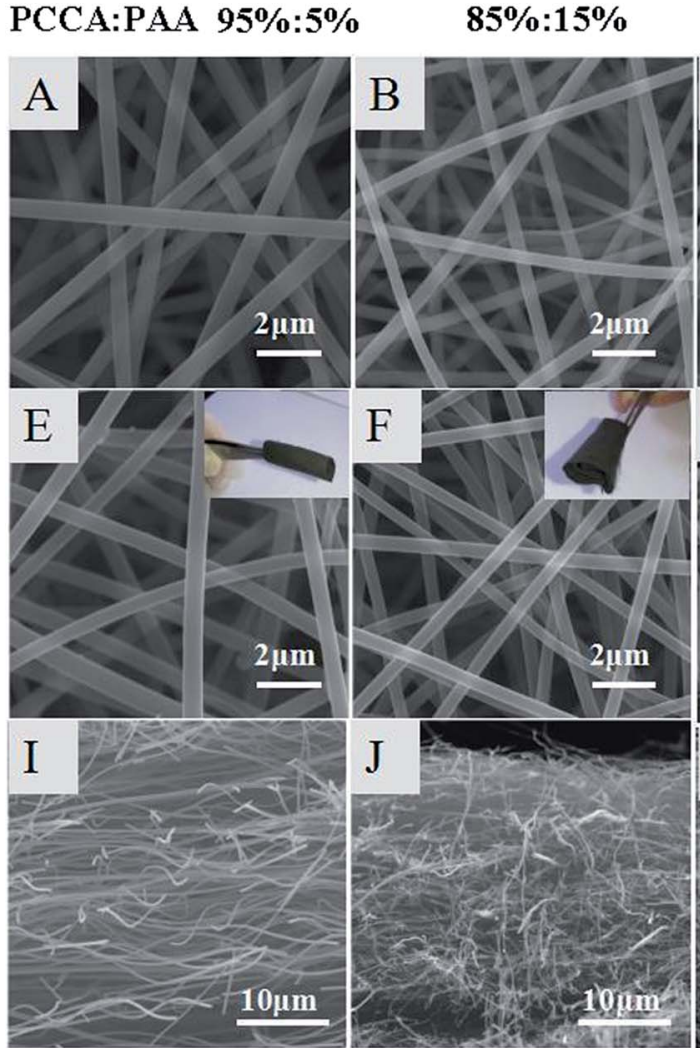

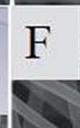

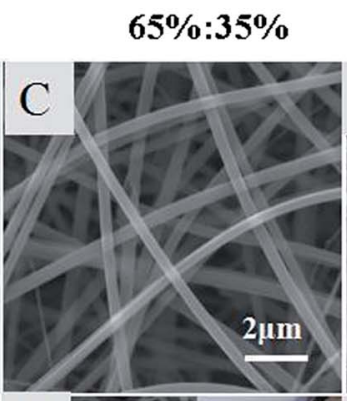
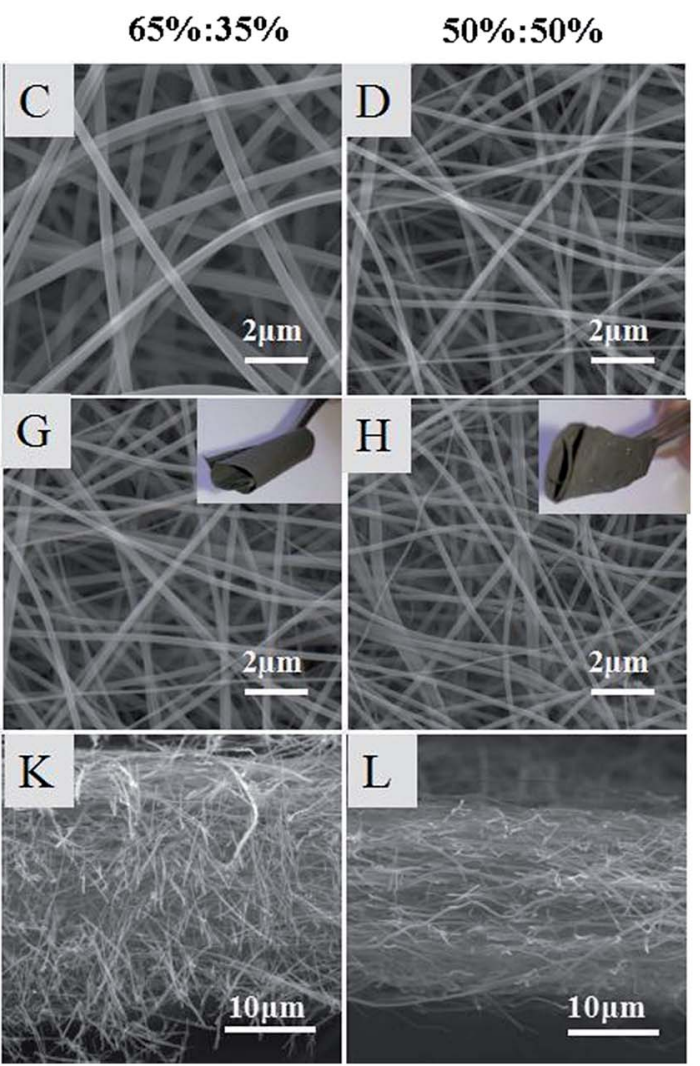

Fig. 3 SEM images of the PCAAS/PAA nanofibers $(A-D)$; $(E-H)$ show their carbon nanofibers, and $(I-L)$ show the longitudinal section views of PBPICF.

is beneficial for the adsorption of the electrolyte and the chargestorage performance of EDLCs. Thermogravimetric analysis (TGA) is used to investigate the thermal stability of PBPICF.
There are significant differences in the thermal stability between PCAAS and PAA (Fig. 4D). For example, PAA displays a platform while PCAAS is weightless between $250{ }^{\circ} \mathrm{C}$ and
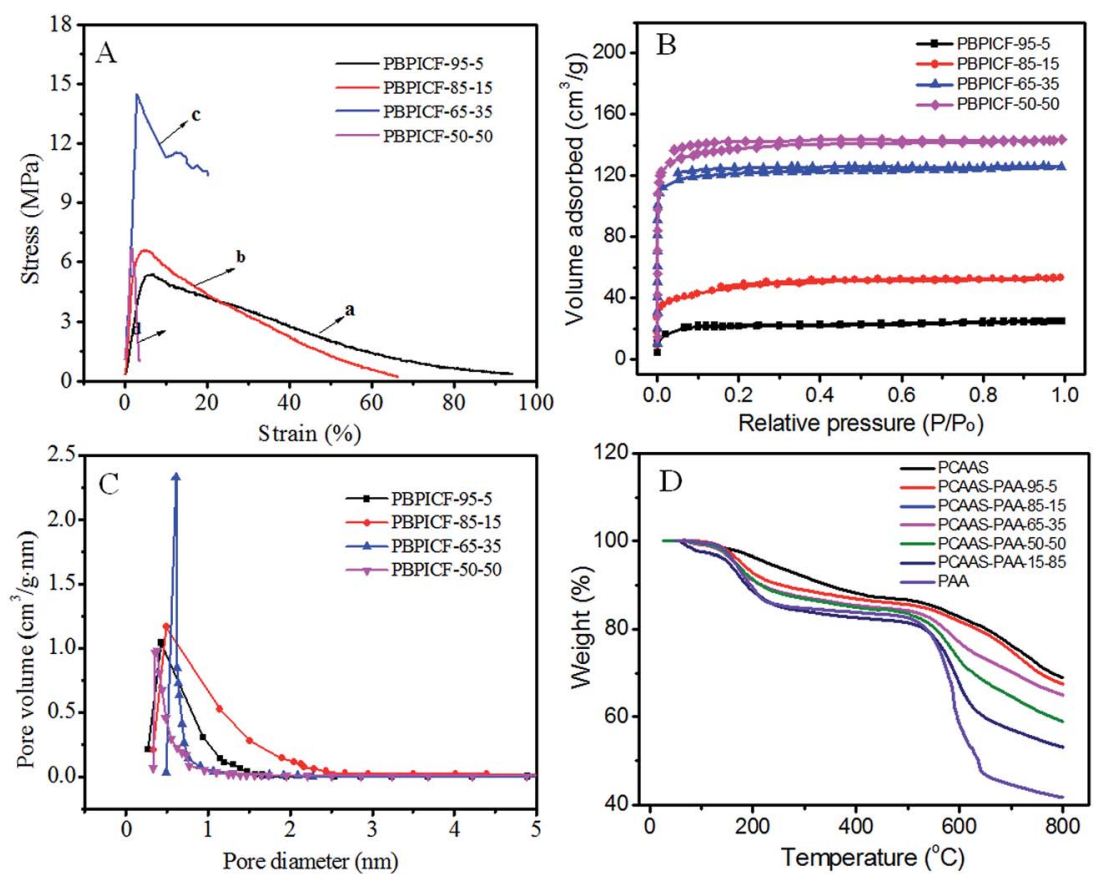

Fig. 4 (A) Stress-strain curves; (B) the isothermal adsorption curves and (C) pore size distribution of PBPICFs; (D) the TGA curves of PCAAS/PAA and PAA nanofibers under a $\mathrm{N}_{2}$ atmosphere. 

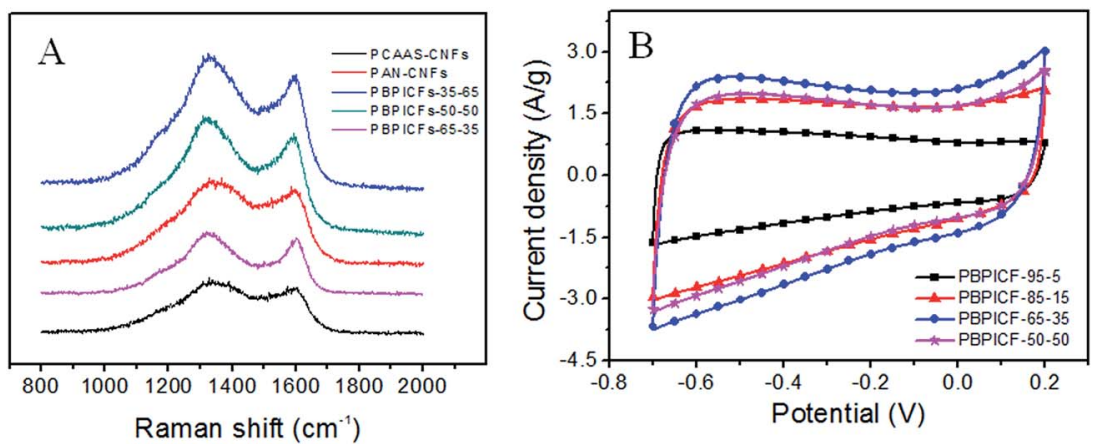

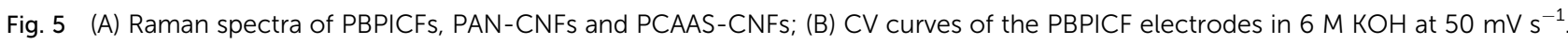

$500{ }^{\circ} \mathrm{C}$. When the temperature is above $520^{\circ} \mathrm{C}$, PAA loses weight drastically. The residual rate of PCAAS $(69.01 \%)$ is significantly higher than that of PAA $(41.75 \%)$ at $800{ }^{\circ} \mathrm{C}$, indicating that there are different thermal weight loss rates, which may result in abundant pores in PBPICF.
Fig. 5A shows the Raman spectra of the carbonized samples. The first band around $1340 \mathrm{~cm}^{-1}$ (D-band) is due to the presence of disordered carbon. Another peak at $1580 \mathrm{~cm}^{-1}$ (G-band) is due to the presence of highly oriented graphitic carbon. The relative intensity ratio of the D-band to G-band, represented as
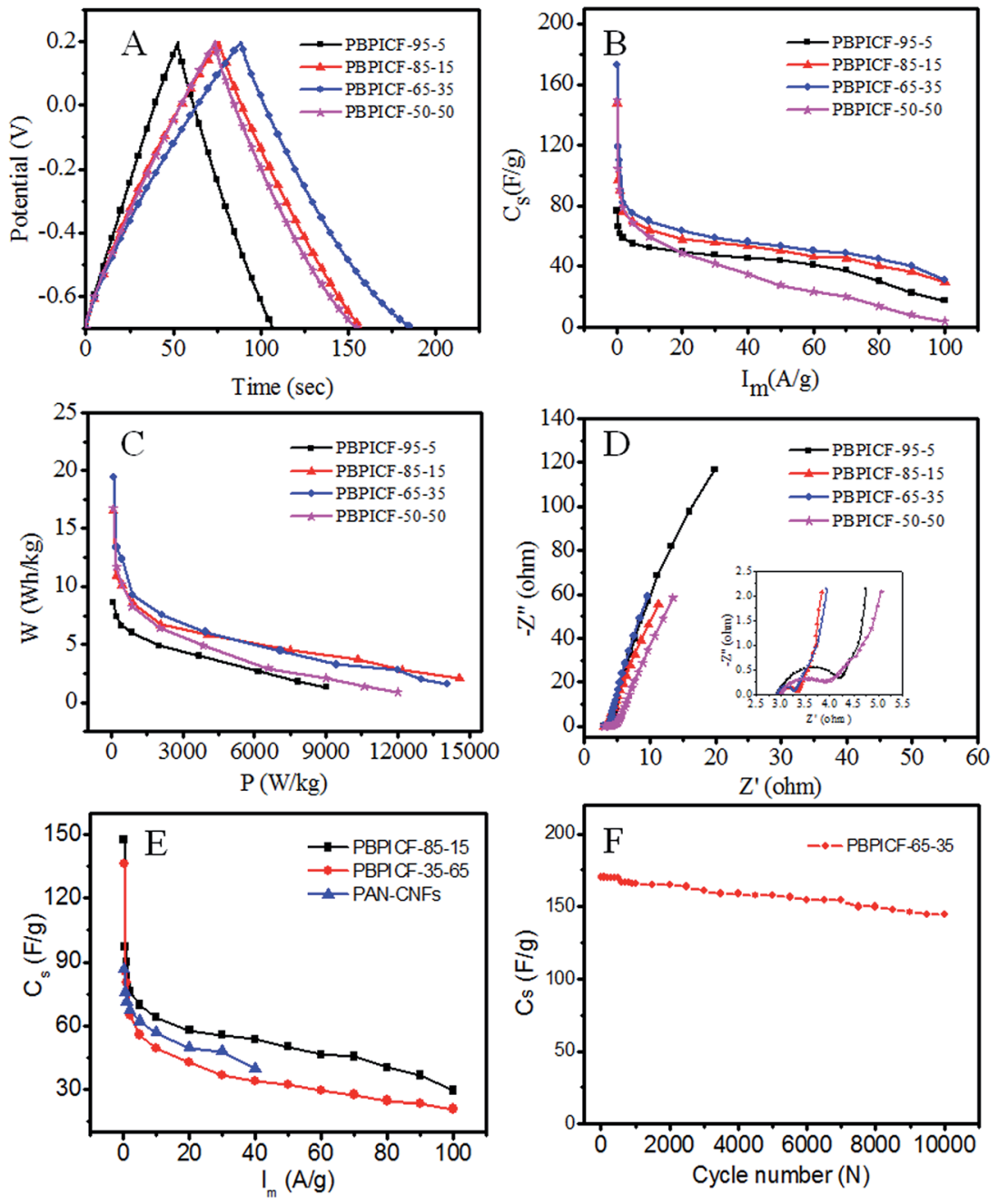

Fig. 6 The electrochemical properties of PBPICF electrodes: (A) constant current charge/discharge curves at 1 A g ${ }^{-1}$; (B) the plots of current density vs. specific capacitance; (C) Ragone plots relative to the corresponding energy and power density; (D) Nyquist plots, inset is the magnified Nyquist plots; (E) rate capability curves of different electrode materials; (F) cycling performance of the PBPICF-65-35 electrode at $1 \mathrm{~A} \mathrm{~g}^{-1}$. 
$I_{\mathrm{D}} / I_{\mathrm{G}}$, depends on the degree of graphitization, and a lower $I_{\mathrm{D}} / I_{\mathrm{G}}$ ratio indicates the existence of a higher amount of ordered graphitic carbon in the sample. The $I_{\mathrm{D}} / I_{\mathrm{G}}$ ratios of PCAAS-CNFs, PAN-CNFs, PBPICF-35-65, PBPICF-50-50 and PBPICF-65-35 are $1.15,1.27,1.46,1.32$ and 1.05 , respectively, suggesting that the cross-linking of PCAAS facilitates the formation of ordered graphitic structures during carbonization. ${ }^{26,27}$

\subsection{Electrochemical characterization}

The CV measurements of PBPICF were performed in $6 \mathrm{M} \mathrm{KOH}$ electrolyte with a potential ranging from -0.7 to $0.2 \mathrm{~V}$. The $\mathrm{CV}$ plots (Fig. 5B) are approximately rectangle shaped, indicating a typical feature of EDLCs. With the content of PI increasing, the integral area of the CV plot increases and decreases after that. Among them, PBPICF-65-35 displays an optimum electrochemical performance for supercapacitors.

Chronopotentiometry tests were carried out to further study the specific capacitance and rate performance. It can be seen that all of the charge/discharge curves are nearly symmetrically triangular. PBPICF-65-35 shows the largest specific capacitance (172.44 $\left.\mathrm{F} \mathrm{g}^{-1}\right)$, which is in accordance with the $\mathrm{CV}$ results (Fig. 5B). Fig. 6A shows the current-specific capacitance $\left(i-C_{\mathrm{s}}\right)$ curves with different current densities. The specific capacitance values of PBPICF-95-5, PBPICF-85-15, PBPICF-65-35 and PBPICF-50-50 are 76.89, 147.56, 172.44 and $149.11 \mathrm{~F} \mathrm{~g}^{-1}$ at $0.2 \mathrm{~A} \mathrm{~g}^{-1}$, respectively. The PBPICF electrodes also display excellent energy and power density (Fig. 6C). PBPICF-65-35 displays a higher energy density compared with other electrodes, and achieves a high value of $19.4 \mathrm{~W} \mathrm{~h} \mathrm{~kg}^{-1}$ at a current density of $0.2 \mathrm{~A} \mathrm{~g}^{-1}$, and the power density is $90 \mathrm{~W} \mathrm{~kg}^{-1}$. These results are superior to those of activated carbon materials. ${ }^{32,33}$

The electrochemical impedance spectroscopy (EIS) measurements were performed to analyze the electrochemical behavior of PBPICF. The results indicated that PBPICF-65-35 has a smaller charge transfer resistance (about $0.38 \Omega$ ) and a more vertical line at low frequencies (Fig. 6D), which suggest a faster charge transport and better electrical conductivity.

In order to study the electrochemical properties of PBPICF further, carbon nanofibers with different raw materials were also compared (Fig. 6E). The results show that PBPICF displays a good specific capacitance at different scan rates, and even PBPICF-85-15 (152.4 $\left.\mathrm{F} \mathrm{g}^{-1}\right)$ is better than polyacrylonitrile (PAN)-based CNFs (86.85 $\mathrm{F} \mathrm{g}^{-1}$ ). Compared with PBPICF-35-65, PBPICF-85-15 is more superior, which may be owed to a higher content of BBB and a better flexibility. Fig. $6 \mathrm{~F}$ shows the cycling performance of PBPICF-65-35. After 10000 cycles, the specific capacitance still remains at 96\%, indicating that PBPICF meets the requirements for high current charge and discharge, and exhibits a good electrochemical stability.

As mentioned above, PBPICF-65-35 displays an optimum electrochemical performance for supercapacitors. The reasons for this may be as follows. (1) PBPICF-65-35 possesses the largest specific surface area $\left(368.0 \mathrm{~m}^{2} \mathrm{~g}^{-1}\right)$ and a relatively concentrated pore size distribution, and its pore size $(0.8 \mathrm{~nm})$ is close to the cation and anion size of the electrolyte $(1.1 \mathrm{~nm}) .{ }^{25}$ The matching of the pore size of PBPICF-65-35 with the ion size of the electrolyte resulted in an increase in the capacitance. (2) Raman data showed that the $I_{\mathrm{D}} / I_{\mathrm{G}}$ ratio of PBPICF-65-35 (1.05) was lower than that of PAN-CNFs (1.27) (Fig. 5A), suggesting that PBPICF-65-35 was beneficial for the formation of more ordered graphitic structures during carbonization. Furthermore, EIS results indicated that PBPICF-65-35 has a smaller charge transfer resistance among the PBPICF composites (Fig. 6D). The increased conductivity in the electrolyte ions helps to decrease the charge transfer resistance between the electrode and the electrolyte.

\section{Conclusions}

In this study, PBPICF membranes were successfully prepared by a facile electrospinning and carbonization process. The 3D porous, fluffy and self-standing PBPICF membranes with good mechanical performance and flexibility can be arbitrarily bent and folded. Such PBPICF membranes were directly used as electrode materials for supercapacitors without any binders. The electrochemical results showed that PBPICF-65-35 displayed the best charge storage performance (172.44 $\mathrm{F} \mathrm{g}^{-1}$, $\left.0.2 \mathrm{~A} \mathrm{~g}^{-1}\right)$. These promising results show potential for these binderless, flexible PBPICF membranes to be used in energy storage systems.

\section{Conflicts of interest}

There are no conflicts to declare.

\section{Acknowledgements}

This research was supported by the National Natural Science Foundation of China (Grants No. 21374044); the Major Special Projects of Jiangxi Provincial Department of Science and Technology (Grant No. 20114ABF05100), the Natural Science Foundation of Jiangxi Province, China (20171BAB213015) and the Technology Plan Landing Project of Jiangxi Provincial Department of Education (GCJ2011-24).

\section{References}

1 A. S. Aricò, P. Bruce, B. Scrosati, J. M. Tarascon and W. van Schalkwijk, Nat. Mater., 2005, 4, 366-377.

2 G. P. Wang, L. Zhang and J. J. Zhang, Chem. Soc. Rev., 2012, 41, 797-828.

3 J. Gamby, P. L. Taberna, P. Simon, J. F. Fauvarque and M. Chesneau, J. Power Sources, 2001, 101, 109-116.

4 V. Subramanian, C. Luo, A. M. Stephan, K. S. Nahm, S. Thomas and B. Wei, J. Phys. Chem. C, 2007, 111, 75277531.

5 M. S. Tam and M. J. Antal, Ind. Eng. Chem. Res., 1999, 38, 4268-4276.

6 J. Li, X. Wang, Q. Huang, S. Gamboa and P. J. Sebastian, J. Power Sources, 2006, 158, 784-788.

7 R. Saliger, U. Fischer, C. Herta and J. Fricke, J. Non-Cryst. Solids, 1998, 225, 81-85. 
8 X. J. Wei, S. G. Wan and S. Y. Gao, Nano Energy, 2016, 28, 206215.

9 Y. Wang, Z. Shi, Y. Huang, Y. Ma, C. Wang, M. Chen and Y. Chen, J. Phys. Chem. C, 2009, 113, 13103-13107.

10 C. G. Liu, Z. N. Yu, D. Neff, A. Zhamu and B. Z. Jang, Nano Lett., 2010, 10, 4863-4868.

11 L. T. Le, M. H. Ervin, H. Qiu, B. E. Fuchs and W. Y. Lee, Electrochem. Commun., 2011, 13, 355-358.

12 M. F. L. De Volder, S. H. Tawfick, R. H. Baughman and A. J. Hart, Science, 2013, 339, 535-539.

13 Q. H. Guo, X. P. Zhou, X. Y. Li, S. L. Chen and H. Q. Hou, J. Mater. Chem., 2009, 19, 2810-2816.

14 E. Frackowiak, K. Metenier, V. Bertagna and F. Beguin, Appl. Phys. Lett., 2000, 77, 2421-2423.

15 C. Kim, Y. O. Choi, W.-J. Lee and K. S. Yang, Electrochim. Acta, 2004, 50, 883-887.

16 K. Leitner, A. Lerf, M. Winter, J. O. Besenhard, S. Villar Rodil, F. Suárez García, A. Martínez Alonso and J. M. D. Tascón, J. Power Sources, 2006, 153, 419-423.

17 J. Li, X. Huang, L. Cui, N. Chen and L. Qu, Prog. Nat. Sci.: Mater. Int., 2016, 26, 212-220.

18 X. Peng, L. L. Peng, C. Z. Wu and Y. Xie, Chem. Soc. Rev., 2014, 43, 3303-3323.

19 M. R. Palacín, Chem. Soc. Rev., 2009, 38, 2565-2575.

20 L. Nyholm, G. Nystrom, A. Mihranyan and M. Stromme, Adv. Mater., 2011, 23, 3751-3769.

21 Y. Y. Horng, Y. C. Lu, Y. K. Hsu, C. C. Chen, L. C. Chen and K. H. Chen, J. Power Sources, 2010, 195, 4418-4422.
22 X. H. Lu, M. H. Yu, G. M. Wang, T. Zhai, S. L. Xie, Y. C. Ling, Y. X. Tong and Y. Li, Adv. Mater., 2013, 25, 267-272.

23 L. Yuan, X. H. Lu, X. Xiao, T. Zhai, J. Dai, F. Zhang, B. Hu, X. Wang, L. Gong, J. Chen, C. Hu, Y. Tong, J. Zhou and Z. L. Wang, ACS Nano, 2012, 6, 656-661.

24 F. J. Miao, C. L. Shao, X. H. Li, N. Lu, K. X. Wang, X. Zhang and Y. C. Liu, Energy, 2016, 95, 233-241.

25 T. H. Le, Y. Yang, L. Yu, T. Gao, Z. H. Huang and F. Y. Kang, J. Appl. Polym. Sci., 2016, 133, 43397-43406.

26 N. C. Abeykoon, V. Garcia, R. A. Jayawickramage, W. Perera, J. Cure, Y. J. Chabal, K. J. Balkusab and J. P. Ferraris, RSC Adv., 2017, 7, 20947-20959.

27 Y. Z. Li, J. Dong, J. X. Zhang, X. Zhao, P. P. Yu, L. Jin and Q. H. Zhang, Small, 2015, 11, 3476-3484.

28 J. G. Liu, X. J. Zhao, H. X. Yang, H. S. Li, L. Fan and S. Y. Yang, Macromol. Chem. Phys., 2006, 207, 1272-1277.

29 A. L. Briseno, S. C. B. Mannsfeld, P. J. Shamberger, F. S. Ohuchi, Z. Bao, S. A. Jenekhe and Y. Xia, Chem. Mater., 2008, 20, 4712-4719.

30 D. J. Lipomi, R. C. Chiechi, M. D. Dickey and G. M. Whitesides, Nano Lett., 2008, 8, 2100-2105.

31 J. Chmiola, G. Yushin, Y. Gogotsi, C. Portet, P. Simon and P. L. Taberna, Science, 2006, 313, 1760-1763.

32 W. Xing, S. Z. Qiao, R. G. Ding, F. Li, G. Q. Lu, Z. F. Yan and H. M. Cheng, Carbon, 2006, 44, 216-224.

33 J. Yang, Y. Liu, X. Chen, Z. Hu and G. Zhao, Acta Phys.-Chim. Sin., 2008, 24, 13-19. 